\title{
Fatigue Properties of Layered Double Hydroxides Modified Asphalt and Its Mixture
}

\author{
Xing Liu, Shaopeng Wu, Ling Pang, Yue Xiao, and Pan Pan \\ State Key Laboratory of Silicate Materials for Architectures, Wuhan University of Technology, Wuhan 430070, China \\ Correspondence should be addressed to Ling Pang; lingpang@whut.edu.cn
}

Received 16 December 2013; Revised 10 March 2014; Accepted 11 March 2014; Published 7 April 2014

Academic Editor: Majid R. Ayatollahi

Copyright (c) 2014 Xing Liu et al. This is an open access article distributed under the Creative Commons Attribution License, which permits unrestricted use, distribution, and reproduction in any medium, provided the original work is properly cited.

\begin{abstract}
This study investigated the influence of layered double hydroxides (LDHs) on the fatigue properties of asphalt mixture. In this paper, different aging levels (thin film oven test (TFOT) and ultraviolet radiation aging (UV aging for short)) of bitumen modified with various mass ratios of the LDHs were investigated. The TFOT and UV aging process were used to simulate short-term field thermaloxidative aging and long-term field light UV aging of bitumen, respectively. The influences of LDHs on the fatigue properties of LDHs were evaluated by dynamic shear rheometer (DSR) and indirect tensile fatigue test. Results indicated that the introduction of LDHs could change the fatigue properties of bitumen under a stress control mode. The mixture with modified bitumen showed better fatigue resistance than the mixture with base bitumen. The results illustrated that the LDHs would be alternative modifiers used in the bitumen to improve the lifetime of asphalt pavements.
\end{abstract}

\section{Introduction}

Bitumen has been widely used in pavement construction as a binder to bond aggregates [1]. Due to its viscoelastic properties, bitumen binder makes the asphalt pavement more flexible and comfortable for driving compared with cement concrete pavement. As a complex mixture of aliphatic, aromatic, and naphthenic hydrocarbons, the properties of bitumen often change gradually during service life due to the vehicle loads and environmental factors $[2,3]$.

Thermal oxygen ageing and ultraviolet radiation (UV) ageing, which are considered as an inevitable process in the practical application of asphalt pavement, have great effect on the fatigue properties of asphalt [4-6]. These two ageing types will decrease the physical properties, particularly fatigue properties at room temperature which will cause many problems in the field $[7,8]$.

In many countries all over the world, traffic loads are increasing not only in number, but also in magnitude. As a result, these increasing vehicle loads accelerate the dete rioration of asphalt pavement and lead to fatigue cracking. The cracking can result in moisture penetration which could weaken the soil foundation. The combined effect of aging, cracks, weakened foundation, and so forth will lead to rapid failure of pavement structures. Therefore, it is meaningful to investigate the fatigue properties in order to extend the fatigue life of asphalt pavement.

Layered double hydroxides (LDHs) have attracted considerable attention as an ultraviolet light resistant material in recent years. These layered materials have multi nestification layered structures. The inorganic layer sheets have the effect of physical shield UV light. Some metal elements of layer sheets and negative ions between layer sheets will chemically absorb UV light. This kind of multichemical absorbability and physical shield effect make the organic material as a material with excellent UV resistant behavior [9-13]. Due to the fundamental structure of LDHs, LDHs has the potential to improve the aging and fatigue resistance of bitumen. As a result, the effect of introducing LDHs into bitumen has received wide attention. Fatigue properties of road materials cannot be ignored due to their important indication of the pavement performance level during the service life of pavement. This study exactly aims at investigating the influence of the LDHs on the fatigue properties of bitumen and mixtures.

\section{Experiments}

2.1. Materials. SK- $90^{\#}$ paving bitumen, provided by SK Corp., Korea, was used as the base material. Its physical properties are given in Table 1. 
TABLE 1: Physical properties of the base bitumen.

\begin{tabular}{lcc}
\hline Characteristic & Unit & Value \\
\hline Penetration $\left[25^{\circ} \mathrm{C}\right]$ & $0.1 \mathrm{~mm}$ & 89 \\
Softening point $[\mathrm{R}$ and $\mathrm{B}]$ & ${ }^{\circ} \mathrm{C}$ & 45.5 \\
Ductility $\left[10^{\circ} \mathrm{C}\right]$ & $\mathrm{cm}$ & 20.3 \\
Performance grade & ${ }^{\circ} \mathrm{C}$ & $64-28$ \\
Dynamic viscosity $\left[60^{\circ} \mathrm{C}\right]$ & $\mathrm{Pa} \cdot \mathrm{s}$ & 158 \\
Dynamic viscosity $\left[135^{\circ} \mathrm{C}\right]\left[10^{-3}\right]$ & $\mathrm{Pa} \cdot \mathrm{s}$ & 430 \\
\hline
\end{tabular}

TABLE 2: Basic properties of basalt aggregate.

\begin{tabular}{lcc}
\hline Characteristic & Unit & Value \\
\hline Specific gravity & $\mathrm{g} / \mathrm{cm}^{3}$ & 2.719 \\
Water absorption ratio & $\%$ & 0.98 \\
Abrasion loss & $\%$ & 18.6 \\
Crushing value & $\%$ & 14.4 \\
\hline
\end{tabular}

LDHs which appeared white, with bulk density of $0.45 \mathrm{~g} / \mathrm{cm}^{3}$, were provided by Rui Fa Chemical Company Limited, Jiangyin, Jiangsu, China. LDHs are a super molecular compound which contains $\mathrm{Mg}$-Al layered double hydroxides complex metallic material. The composition of LDHs is as follows:

$$
\mathrm{Mg}_{1-x} \mathrm{Al}_{x}(\mathrm{OH})_{2}\left(\mathrm{CO}_{3}\right)_{x / 2} \cdot \mathrm{mH}_{2} \mathrm{O}
$$

where $x$ is the content variation of metallic elements, $0.2 \leq$ $x \leq 0.33 ; m$ is the amount of crystal water, $0 \leq m \leq 2$.

Basalt aggregate used in this study was obtained from Tongliao, Inner Mongolia, China. Table 2 gives the basic physical properties of basalt aggregate.

2.2. Preparation of LDHs Modified Bitumen and Mixture. The modified bitumen was prepared by using a laboratory high shear mixer. Bitumen was first heated to a well fluid at around $140^{\circ} \mathrm{C}$ in the mixer. Then a certain amount of LDHs was added to bitumen and blended at $4000 \mathrm{r} / \mathrm{min}$ rotation speed for about $60 \mathrm{~min}$ to ensure homogeneous dispersion. The unmodified bitumen was also processed under these same mix conditions to ensure that the comparison is reasonable.

AC-16C mixture type, designed by Marshall methods, was adopted. The basalt aggregates gradation is shown in Figure 1. Based on the primary design procedure, the optimum bitumen content was concluded at $5.0 \%$ by weight of aggregates. In this study, all the asphalt mixture samples used for following research were prepared by Marshall samples and were cut into specimens with thickness of $40 \mathrm{~mm}$.

2.3. Aging Procedures. All bitumen samples were separately aged by TFOT and UV ageing. The TFOT ageing procedure was conducted according to ASTM D 1754 [14], while the UV ageing experiment conditions are showed in Table 3.

The uncompacted asphalt mixtures were separately aged by oven ageing at $135^{\circ} \mathrm{C}$ for 5 hours and UV aging for 8 days. The same UV strength as used for bitumen binder was used. But the UV radiation can just age asphalt mixture within certain depth [15]. Therefore, during the UV aging,

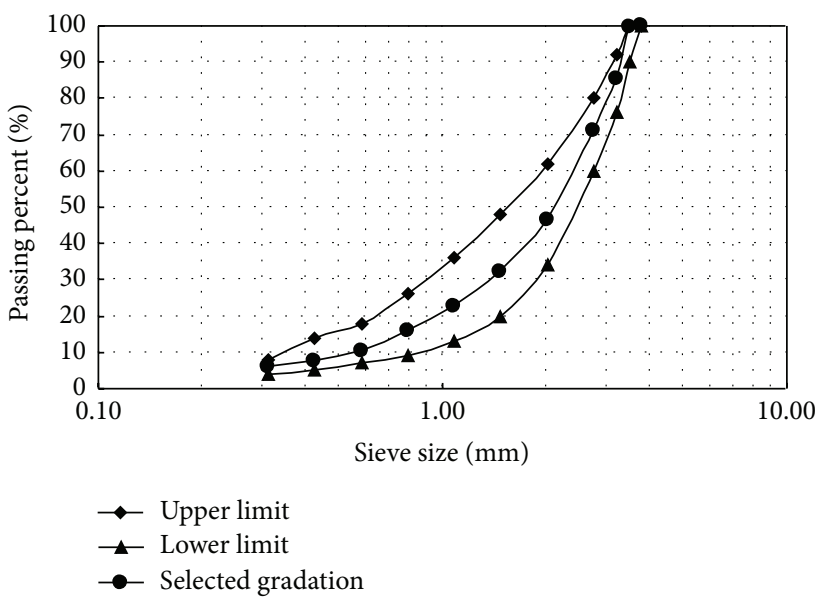

FIGURE 1: Aggregates gradation curves for asphalt mixture.

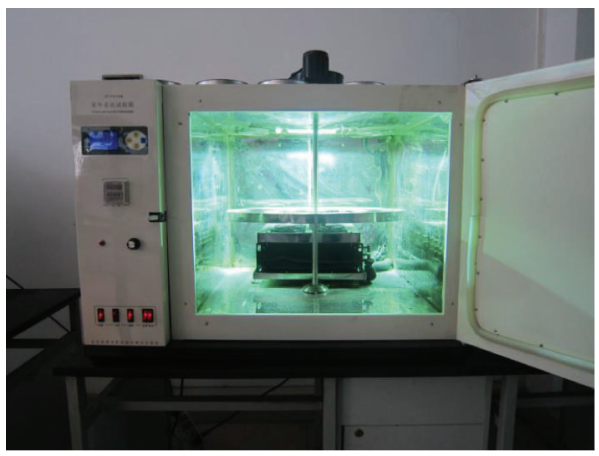

FIGURE 2: UV simulation machine with asphalt mixture in it.

TABLE 3: UV aging test conditions for bitumen binder.

\begin{tabular}{lccc}
\hline Temperature & UV strength & Film thickness & Aging time \\
\hline $50^{\circ} \mathrm{C}$ & $10,000 \mu \mathrm{W} / \mathrm{cm}^{2}$ & $1250 \mu \mathrm{m}$ & 8 days \\
\hline
\end{tabular}

the uncompacted asphalt mixtures were turned over every 12 hours. The UV aging was completed in the UV simulation machine as Figure 2 shows.

2.4. Test Methods. The physical properties of SK- $90^{\#}$ bitumen and LDHs modified bitumen, including penetration $\left(25^{\circ} \mathrm{C}\right)$, softening point (ring and ball method), and ductility $\left(10^{\circ} \mathrm{C}\right)$, were investigated according to the standard ASTM D5 [16], ASTM D36 [17], and ASTM D113 [18], respectively.

Dynamic shear rheometer (DSR) MCR101 from Austria Anton Paar Company was used in this study to test the fatigue properties of bitumen binder [19]. The shear geometry of $8 \mathrm{~mm}$ diameter with $2 \mathrm{~mm}$ gap of bitumen binder was used. The testing frequency was fixed at $10 \mathrm{~Hz}$, while the stress control mode of 0.5 and $0.8 \mathrm{MPa}$ was applied.

Universal testing machine (UTM-25) was used in the mixture fatigue test [20] according to AASHTO T322-03. Figure 3 shows the specimen loading apparatus and deformation sensor mounting system in the UTM-25. The load with a resolution of $1 \mathrm{~N}$ was applied over the specimen through the upper strip with a width of $12.5 \mathrm{~mm}$. The lower strip with the 
TABLE 4: Detailed parameters used in the mixture fatigue test.

\begin{tabular}{lc}
\hline Temperature $\left[{ }^{\circ} \mathrm{C}\right]$ & 5 \\
Frequency $[\mathrm{Hz}]$ & 2 \\
Stress ratio ${ }^{*}\left[5^{\circ} \mathrm{C}\right]$ & $0.4,0.5,0.6,0.65$ \\
Waveform & A haversine plus a rest period \\
Pulse width $[\mathrm{ms}]$ & 63 \\
\hline${ }^{*}$ Stress ratio is the ratio of the
\end{tabular}

${ }^{*}$ Stress ratio is the ratio of the loading stress and cleavage strength.

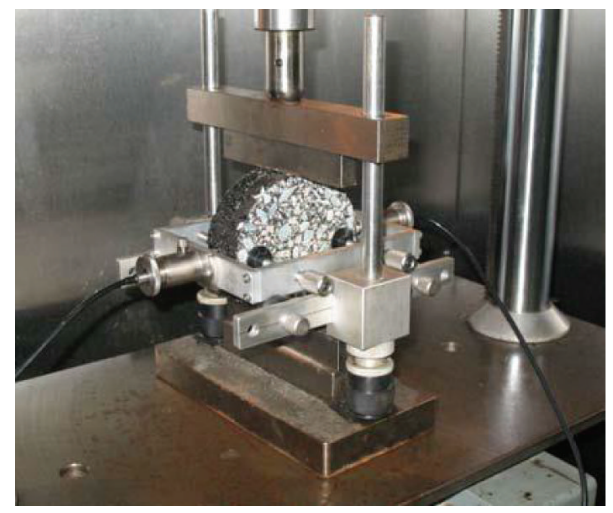

FIGURE 3: Indirect tensile testing device for the fatigue test and indirect tensile modulus test.

same width was fixed firmly to the base plate. Two horizontal sensors were recording horizontal deformations within the range of $\pm 0.5 \mu \mathrm{m}$. The vertical sensor was capable of recording the vertical deformation within a range of $\pm 1.0 \mu \mathrm{m}$. The test was performed in a temperature-controlled cabinet which can control the temperature within $\pm 0.1^{\circ} \mathrm{C}$. Detailed testing conditions are given in Table 4 . The cleavage strength of the mixture is the strength of the material damage.

The uniform tensile stress over most of the height of specimen mainly contributed to the fatigue damage of the specimen. Testing temperature of $5^{\circ} \mathrm{C}$ was chosen for the fatigue tests, and the applied tensile stress was taken lower than the tensile strength.

\section{Results and Discussions}

3.1. Basic Physical Properties. The softening point and penetration of SK-90\# bitumen, 3\% LDHs, and 5\% LDHs modified bitumen before and after aging were shown in Figures 4 and 5. Firstly, when the LDHs were added to bitumen binder, it is obvious to see that the softening point increased slightly and the penetration reduced in a certain degree. Secondly, the more the ratio of LDHs in the bitumen binder, the higher the increment or reduction. The change of these basic physical properties demonstrated that adding small amount of LDHs to bitumen will let the bitumen get harder. It might improve the high temperature property and worsen the low temperature property. The retained penetration ratio of LDHs modified bitumen was higher, while the softening point increment of LDHs modified bitumen was lower after UV aging, compared to base bitumen. In general, the changes of softening point and penetration of LDHs modified bitumen

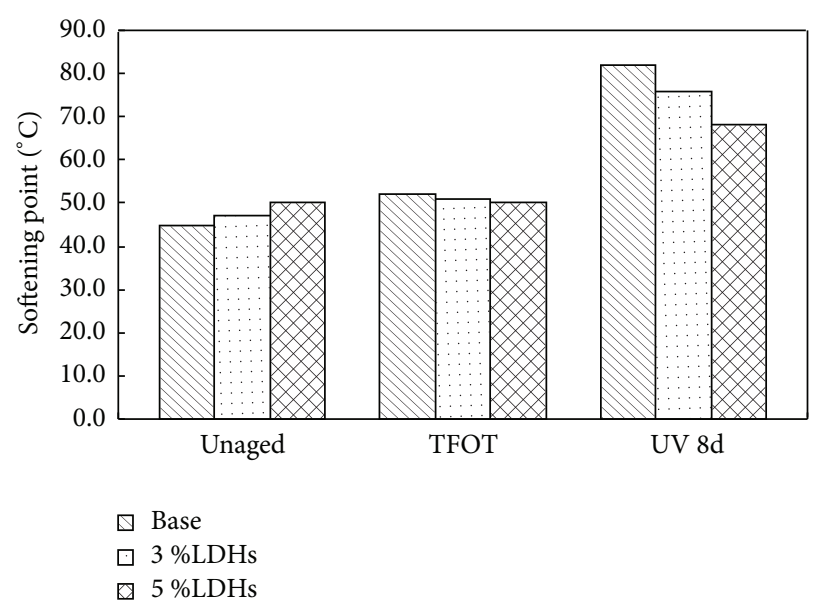

FIGURE 4: Softening point of bitumen.

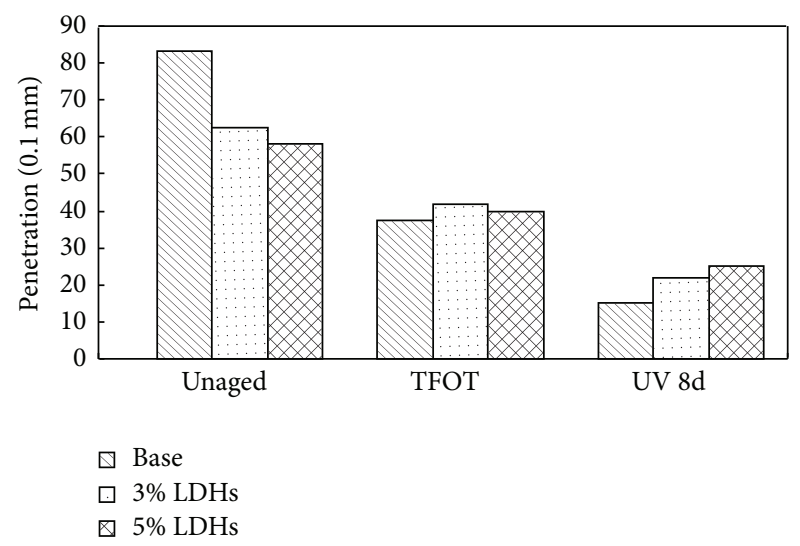

Figure 5: Penetration of bitumen.

after TFOT aging and UV 8d aging were much smaller than the changes of SK- $90^{\#}$ bitumen. This illustrated that the modified bitumen had much better performances than the base bitumen such as temperature sensibility, oxidation ageing resistance, and UV aging resistance. Bitumen modified with $5 \%$ of LDHs slightly behaved better than 3\% LDHs modified bitumen.

3.2. Fatigue Behavior of Bitumen. The fatigue life of bitumen after UV aging was evaluated by DSR at $10^{\circ} \mathrm{C}$. Figures 6 and 7 present the fatigue curves as the function of stress level $0.5 \mathrm{MPa}$ and $0.8 \mathrm{MPa}$ for bitumen after UV $8 \mathrm{~d}$ aging, respectively. The fatigue life of $\mathrm{LDH}$ modified bitumen is much longer than that of base bitumen. Particularly at lower stress level, these differences are much more remarkable. The fatigue life of $3 \%$ LDHs modified bitumen is about $60 \%$ longer and 5\% LDHs modified bitumen is nearly 2.5 times longer compared to the base bitumen at the lower stress level. At higher stress level, all bitumen becomes worse to resist fatigue crack propagation. The contribution to the fatigue life from LDHs at higher stress level is not as obvious as at low stress level. But the fatigue lives of 3\% LDHs modified bitumen and $5 \%$ LDHs modified bitumen were slightly longer than the fatigue life of base bitumen. 


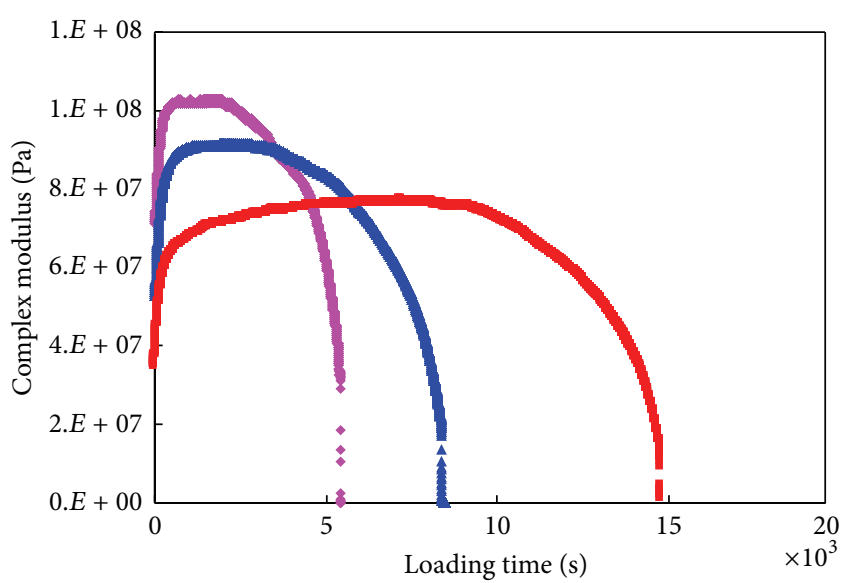

- Base-UV 8d

4 $3 \%$ LDHs-UV $8 \mathrm{~d}$

- $5 \%$ LDHs-UV $8 \mathrm{~d}$

FIGURE 6: Fatigue life as the function of stress level 0.5 MPa after UV $8 \mathrm{~d}$ aging.

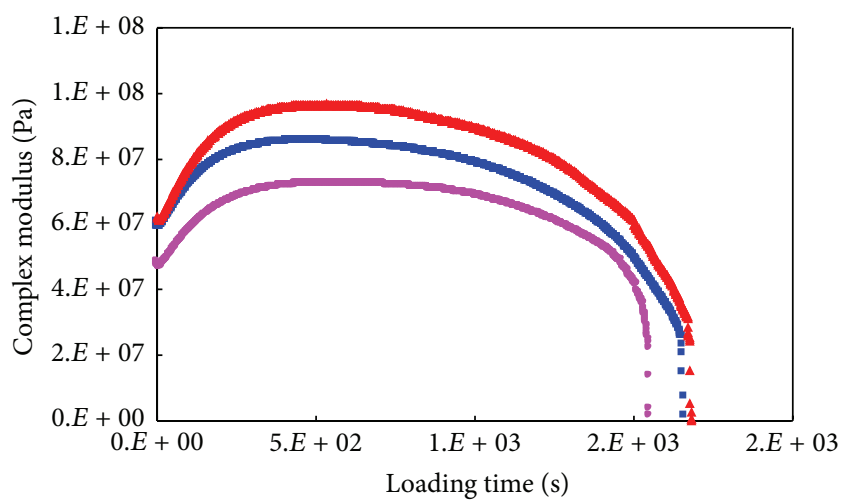

- Base-UV 8d

- $3 \%$ LDHs-UV $8 \mathrm{~d}$

4 $5 \%$ LDHs-UV $8 \mathrm{~d}$

Figure 7: Fatigue life as the function of stress level 0.8 MPa after UV $8 d$ aging.

The dispersing structures of LDHs in bitumen have contribution to the UV aging resistance of LDHs modified bitumen. The dispersion of structures corresponds to wellordered multilayered structures where the bitumen chains are protected by the layer sheets and ions between the layers. The infiltration of oxygen and UV light could be obstructed by the layers in modified bitumen and the energy of UV light that gets into bitumen is therefore reduced. The dispersion and penetration process of oxygen and UV light in modified bitumen was more difficult. So the aging effect was reduced. Therefore, the fatigue life of bitumen can be extended by modifying with LDHs.

3.3. Fatigue Behavior of Asphalt Mixture. Compared with the bitumen, the fatigue behaviour of the mixture was more complicated. Asphalt mixture is a complicated system with aggregates, binder, and voids as the three main functional sections. The fatigue life of mix is not just a combined contribution from all of the composites in the mixture, but also the interlock structure of the skeleton. The property of bitumen binder dominates viscoelastic property of mix. As a result, the fatigue life of mixture is also highly dependent on the binder behavior. The contribution of bitumen to the mixture's fatigue resistance was related to the load level [21]. Therefore, fatigue tests were conducted at several stress levels in this research.

3.3.1. Indirect Tensile Modulus of Asphalt Mixture. The indirect tensile modulus of asphalt mixture is calculated as follows:

$$
\begin{gathered}
M_{R}=\frac{P(\nu+0.27)}{t \Delta H}, \\
\Delta H=\frac{(\nu+0.27)}{3.59 \times \Delta V},
\end{gathered}
$$

where $M_{R}$ is the initial resilience modulus, MPa; $P$ is the load, $\mathrm{N} ; \nu$ is Poisson's ratio; $t$ is the thickness of specimen, $\mathrm{mm}$; $\Delta H$ is the transverse resilience deformation, $\mathrm{mm} ; \Delta V$ is the longitudinal resilience deformation, $\mathrm{mm}$.

Temperature has a great influence on Poisson's ratio of mixture. The higher the temperature, the higher the Poisson ratio. Conversely, the lower the temperature, the lower the Poisson ratio. Based on the technical experiences, the Poisson ratio of 0.25 at $5^{\circ} \mathrm{C}$ was used for asphalt mixture.

Figure 8 shows the indirect tensile modulus of mixture specimens under different stress level at $5^{\circ} \mathrm{C}$. With the loading stress increasing, the indirect tensile modulus of asphalt mixture will increase at $5^{\circ} \mathrm{C}$. Figure 8 indicates that the introduction of $\mathrm{LDHs}$ can decrease the indirect tensile modulus of mixture at $5^{\circ} \mathrm{C}$. Lower indirect tensile modulus of asphalt mixture gives better resistance to deformation and internal stresses. Moreover, UV aging can increase the indirect tensile modulus of the asphalt mixture. There are no obvious differences of the increased percentage from unaged binder to UV aged binder between base bitumen and LDHs modified bitumen.

3.3.2. Fatigue Life of Asphalt Mixture. The fatigue life of asphalt mixture is calculated by the following classical fatigue equation [22]:

$$
N_{f}=K\left(\frac{1}{\sigma_{0}}\right)^{n}
$$

where $N_{f}$ is the fatigue life; $\sigma_{0}$ is the load stress, MPa; $K$ and $n$ are regression coefficients which are solved by the test results.

Table 5 presents the indirect tensile fatigue life of all asphalt mixture specimens at $5^{\circ} \mathrm{C}$. Figure 9 shows the fatigue life and loading stress double logarithmic diagram. A good linear relationship between the stress level and fatigue life with logarithm transformation can be reached at $5^{\circ} \mathrm{C}$.

Under the increasing stress level, the fatigue life decreases with different extent for different asphalt mixture. Under the same conditions, the LDHs modified asphalt mixture has 


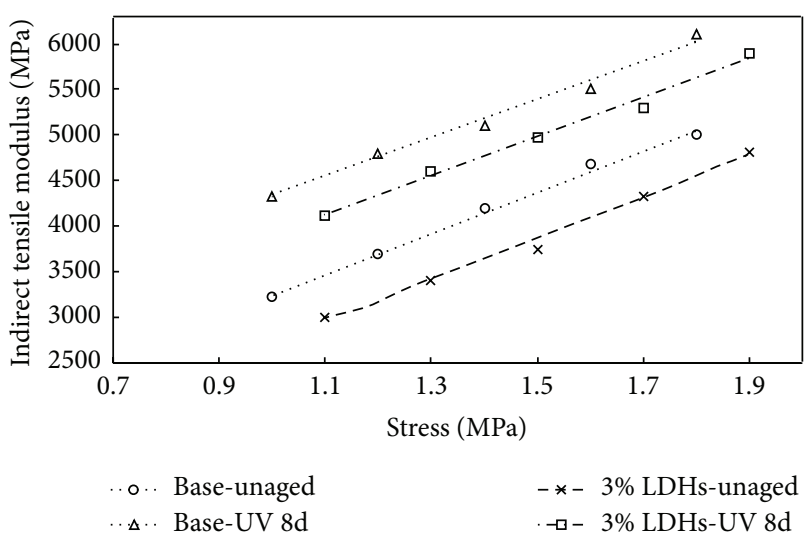

FIGURE 8: Indirect tensile modulus of mixture specimens under different stress level at $5^{\circ} \mathrm{C}$.

TABLE 5: Indirect tensile fatigue life of asphalt mixture specimens at $5^{\circ} \mathrm{C}$.

\begin{tabular}{lccc}
\hline Material types & Stress ratio & Stress [MPa] & Fatigue life \\
\hline \multirow{3}{*}{ Base-unaged } & 0.4 & 1.040 & 89627 \\
& 0.5 & 1.300 & 37076 \\
& 0.6 & 1.560 & 14571 \\
& 0.65 & 1.690 & 8596 \\
\hline \multirow{2}{*}{ Base-UV 8d } & 0.4 & 1.204 & 9746 \\
& 0.5 & 1.505 & 4587 \\
& 0.6 & 1.806 & 1471 \\
& 0.65 & 1.957 & 872 \\
\hline \multirow{3}{*}{ 3\% LDHs-unaged } & 0.4 & 1.052 & 159127 \\
& 0.5 & 1.315 & 45186 \\
& 0.6 & 1.578 & 16317 \\
& 0.65 & 1.710 & 10102 \\
\hline \multirow{3}{*}{ 3\% LDHs-UV 8d } & 0.4 & 1.200 & 18541 \\
& 0.5 & 1.500 & 5540 \\
& 0.6 & 1.800 & 1845 \\
& 0.65 & 1.950 & 1078 \\
\hline
\end{tabular}

longer fatigue life than that of base asphalt mixture. After the same period of UV aging, the fatigue life of LDHs modified asphalt mixture is still longer than that of base asphalt mixture. Therefore, it can be concluded that the introduction of LDHs can improve the fatigue life of asphalt mixture.

According to Figure 9, the fatigue equations are regressed and the regression coefficients of $K$ and $n$ are also obtained. Table 6 presents the regression coefficients of fatigue equation at $5^{\circ} \mathrm{C}$. The parameter $K$ represents the durability of asphalt mixture. The higher the value of $K$, the better the durability of asphalt mixture. The parameter $n$ represents the sensitivity of the influence of stress ratio on the fatigue life. The higher the value of $n$, the more sensitive the influence of stress ratio on the fatigue life.

Firstly, after UV $8 \mathrm{~d}$ aging, the value of $K$ decreases and the value of $n$ increases. It indicates that $\mathrm{UV}$ aging will worsen the durability of the asphalt mixture and increase the sensitivity of the influence of stress ratio on the fatigue life. Secondly, before and after UV aging, the LDHs modified asphalt

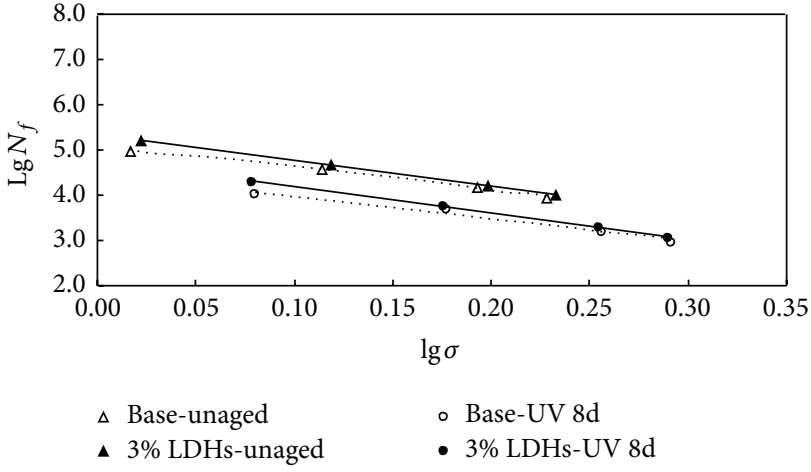

Figure 9: Double logarithmic diagram of fatigue life and loading stress at $5^{\circ} \mathrm{C}$.

mixture has a higher $K$ and $n$ than base asphalt mixture. On the one hand, it demonstrates that the introduction of LDHs can enhance the durability of the asphalt mixture. On the other hand, it also illustrates that the introduction will let fatigue life of the mixture become more sensitive to the stress ratio on the fatigue life.

\section{Conclusions}

This paper investigated the fatigue properties of LDHs modified bitumen and asphalt mixture. Fatigue tests on bitumen binder and asphalt mixture were conducted by means of repeated shear test and indirect tensile fatigue test. The following conclusions can be drawn based on the results that are discussed above.

(1) The changes of softening point and penetration of LDHs modified bitumen after TFOT aging and UV 8d aging were much smaller than the changes of SK- $90^{\#}$ bitumen. This illustrated that the modified bitumen had much better resistance to oxidation and UV than the base bitumen.

(2) Repeated shear test on bitumen binder illustrates that adding LDHs to bitumen binder can improve its fatigue properties under a stress control mode. LDHs can increase the fatigue resistance of bitumen, the fatigue life of $3 \%$ LDHs modified bitumen is more than $60 \%$ longer, and $5 \% \mathrm{LDHs}$ modified bitumen is nearly 2.5 times longer than the fatigue life of base bitumen at the lower stress level.

(3) The introduction of LDHs can decrease the indirect tensile modulus of mixture after UV aging. This means that LDHs might enhance the crack resistance at lower temperature conditions.

(4) Fatigue results of bitumen and mixture with the addition of LDHs imply an improvement in the fatigue behavior of asphalt pavement. The introduction of LDHs into asphalt mixture can enhance its durability but will also increase the stress ratio sensitivity.

About all, the LDHs would be alternative modifiers used for the bitumen to improve the lifetime of asphalt pavements. 
TABLE 6: Regression coefficients of fatigue equation at $5^{\circ} \mathrm{C}$.

\begin{tabular}{|c|c|c|c|c|}
\hline \multirow{2}{*}{ Material types } & \multirow{2}{*}{ Fatigue equation } & \multicolumn{2}{|c|}{ Regression coefficient } & \multirow{2}{*}{$R^{2}$} \\
\hline & & K & $n$ & \\
\hline Base-unaged & $\lg N_{f}=5.0641-4.7775 \lg \sigma$ & $1.16 E+05$ & 4.7775 & 0.9909 \\
\hline Base-UV 8d & $\lg N_{f}=4.4474-4.9993 \lg \sigma$ & $2.80 E+04$ & 4.9993 & 0.9764 \\
\hline 3\% LDHs-unaged & $\lg N_{f}=5.3276-5.6591 \lg \sigma$ & $2.13 E+05$ & 5.6591 & 0.9999 \\
\hline 3\% LDHs-UV 8d & $\lg N_{f}=4.7458-5.8369 \lg \sigma$ & $5.57 E+04$ & 5.8369 & 0.9984 \\
\hline
\end{tabular}

However, the test results listed in this research are limited on two kinds of fatigue test; further research is recommended to prove the conclusions.

\section{Conflict of Interests}

The authors declare that there is no conflict of interests.

\section{Acknowledgments}

This work is supported by National Project of Scientific and Technical Supporting Programs funded by Ministry of Science \& Technology of China (no. 2011BAE28B03) and National Natural Science Foundation of China (no. 51278392). The authors gratefully acknowledge their financial support.

\section{References}

[1] C. Ouyang, S. Wang, Y. Zhang, and Y. Zhang, "Preparation and properties of styrene-butadiene-styrene copolymer/ kaolinite clay compound and asphalt modified with the compound," Polymer Degradation and Stability, vol. 87, no. 2, pp. 309-317, 2005.

[2] J. C. Petersen, "Chemical composition of asphalt as related to asphalt durability. State of the art," Transportation Research Record, no. 999, pp. 13-30, 1984.

[3] W. J. Halstead, "Relation of asphalt chemistry to physical properties and specification," Association of Asphalt Paving Technologists, vol. 54, pp. 91-117, 1985.

[4] C. Ouyang, S. Wang, Y. Zhang, and Y. Zhang, "Improving the aging resistance of asphalt by addition of zinc dialkyldithiophosphate," Fuel, vol. 85, no. 7-8, pp. 1060-1066, 2006.

[5] G. D. Airey and B. Rahimzadeh, "Combined bituminous binder and mixture linear rheological properties," Construction and Building Materials, vol. 18, no. 7, pp. 535-548, 2004.

[6] J. Yu, X. Zeng, S. Wu, L. Wang, and G. Liu, "Preparation and properties of montmorillonite modified asphalts," Materials Science and Engineering A, vol. 447, no. 1-2, pp. 233-238, 2007.

[7] X. Lu and U. Isacsson, "Effect of ageing on bitumen chemistry and rheology," Construction and Building Materials, vol. 16, no. 1, pp. 15-22, 2002.

[8] F. Durrieu, F. Farcas, and V. Mouillet, "The influence of UV aging of a Styrene/Butadiene/Styrene modified bitumen: comparison between laboratory and on site aging," Fuel, vol. 86, no. 10-11, pp. 1446-1451, 2007.

[9] H. Chai, X. Xu, Y. Lin, D. G. Evans, and D. Li, "Synthesis and UV absorption properties of 2,3-dihydroxynaphthalene-6-sulfonate anion-intercalated Zn-Al layered double hydroxides," Polymer Degradation and Stability, vol. 94, no. 4, pp. 744-749, 2009.
[10] Y. Feng, D. Li, Y. Wang, D. G. Evans, and X. Duan, "Synthesis and characterization of a UV absorbent-intercalated Zn-Al layered double hydroxide," Polymer Degradation and Stability, vol. 91, no. 4, pp. 789-794, 2006.

[11] L. Zhang, Y. Lin, Z. Tuo, D. G. Evans, and D. Li, "Synthesis and UV absorption properties of 5-sulfosalicylate-intercalated ZnAl layered double hydroxides," Journal of Solid State Chemistry, vol. 180, no. 4, pp. 1230-1235, 2007.

[12] B. Wang, H. Zhang, D. G. Evans, and X. Duan, "Surface modification of layered double hydroxides and incorporation of hydrophobic organic compounds," Materials Chemistry and Physics, vol. 92, no. 1, pp. 190-196, 2005.

[13] A. N. Ay, B. Zümreoglu-Karan, A. Temel, and L. Mafra, "Layered double hydroxides with interlayer borate anions: a critical evaluation of synthesis methodology and $\mathrm{pH}$-independent orientations in nano-galleries," Applied Clay Science, vol. 51, no. 3, pp. 308-316, 2011.

[14] ASTM D 1754/D1754M-09. Standard test method for Thin Film Oven Test of bituminous materials.

[15] Z. Feng, Study of anti-ultraviolet aging performance of asphalt and aggregate [Ph.D. dissertation], Harbin Institute of Technology, Harbin, China, 2004.

[16] ASTM D5-06. Standard test method for penetration of bituminous materials.

[17] ASTM D36-09. Standard test method for softening point of bitumen (ring-and-ball apparatus).

[18] ASTM D113-07. Standard test method for ductility of bituminous materials.

[19] D. A. Anderson, Y. M. Le Hir, M. O. Marasteanu, J.-P. Planche, D. Martin, and G. Gauthier, "Evaluation of fatigue criteria for asphalt binders," Transportation Research Record, no. 1766, pp. 48-55, 2001.

[20] K. A. Ghuzlan and S. H. Carpenter, "Energy-derived, damagebased failure criterion for fatigue testing," Transportation Research Record, no. 1723, pp. 141-149, 2000.

[21] G. Liu, Characterization and identification of bitumen with the modification of montmorillonite nanoclay [Ph.D. thesis], Delft University of Technology, 2012.

[22] A. S. Adedimila and T. W. Kennedy, "Repeated-load indirect tensile fatigue characteristics of asphalt mixtures," Transportation Research Record, no. 595, pp. 25-33, 1976. 

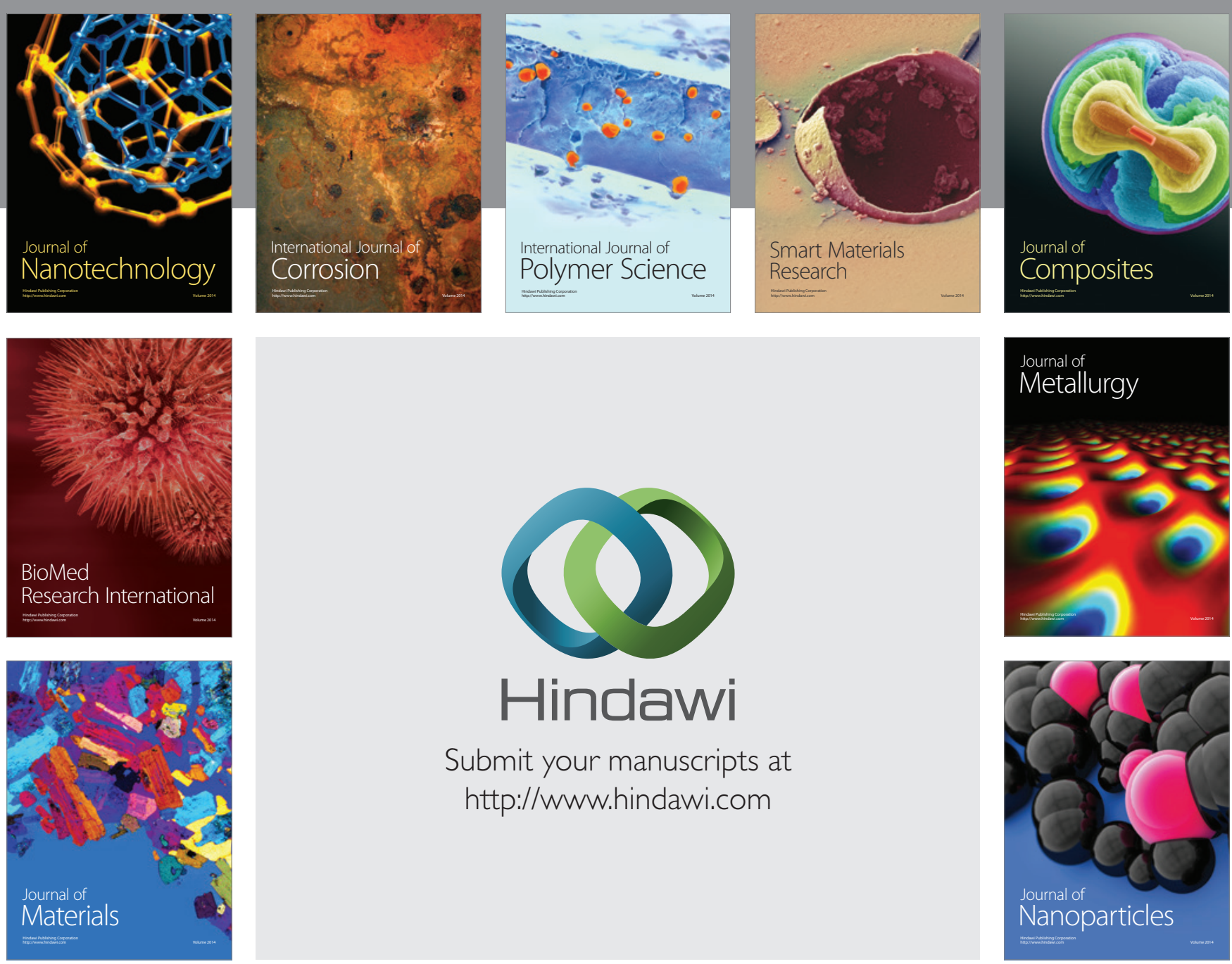

Submit your manuscripts at http://www.hindawi.com
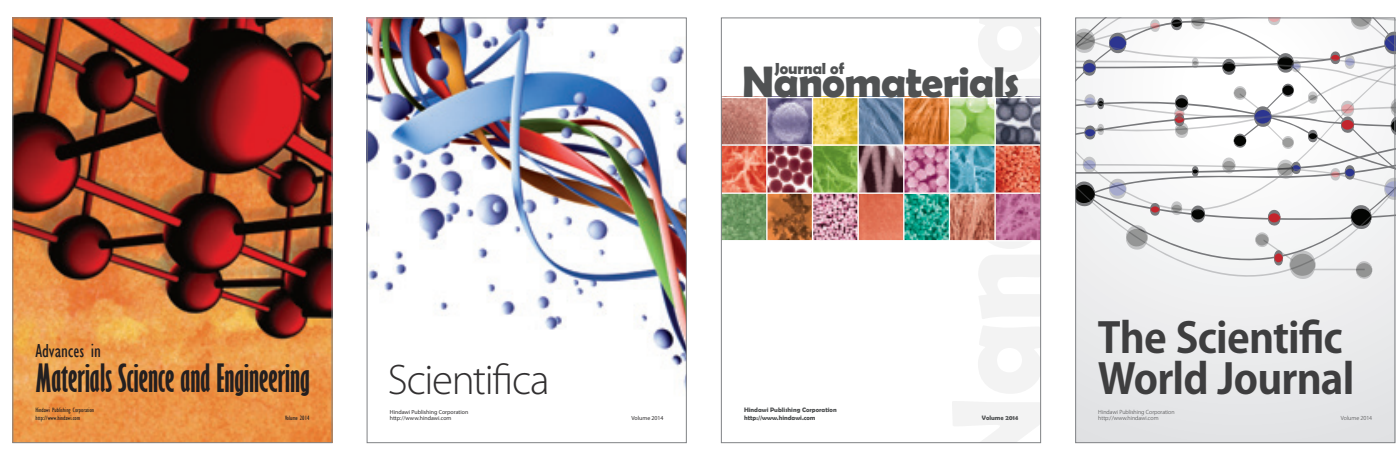

\section{The Scientific World Journal}
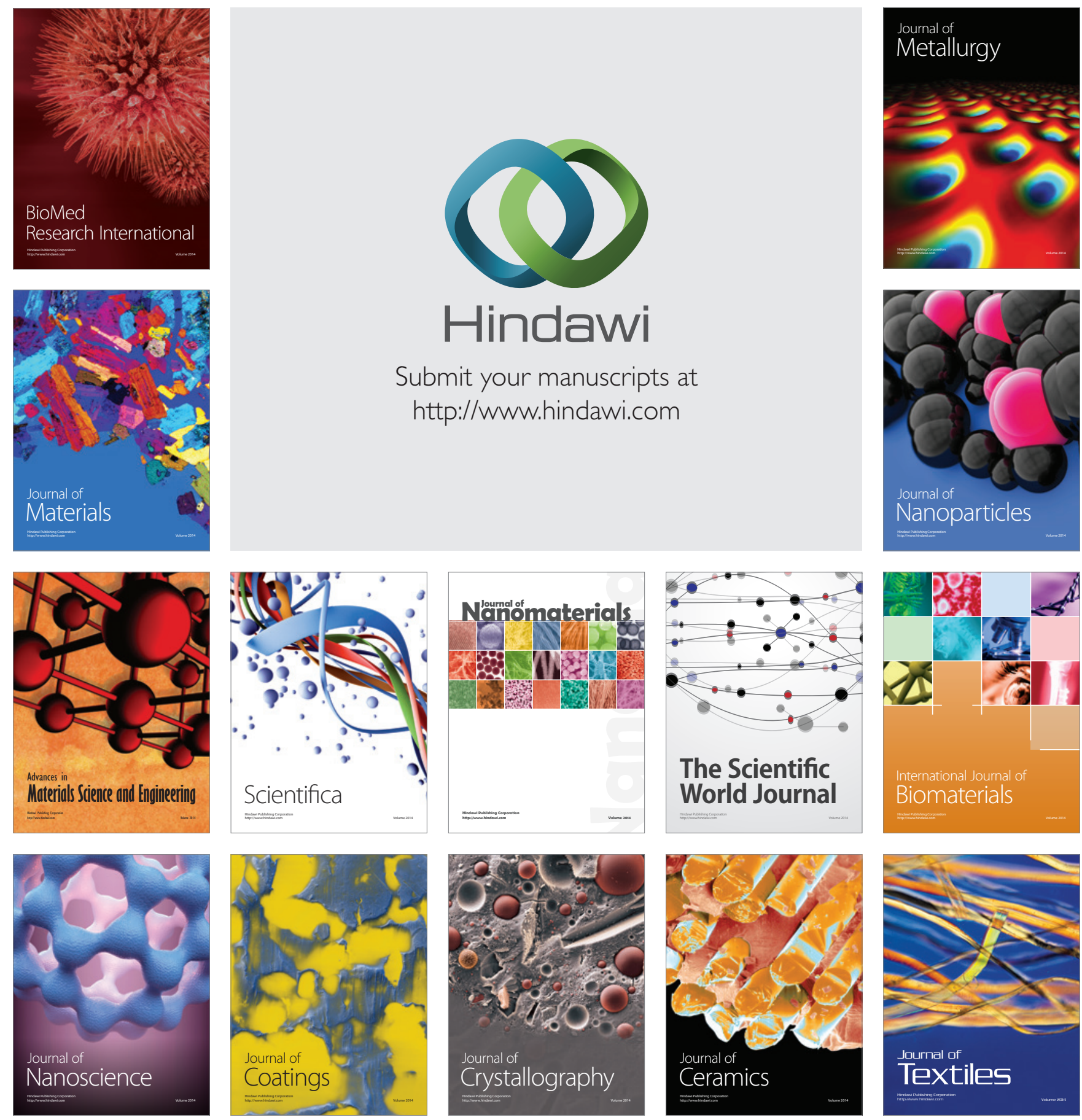